\title{
Recombinant Colony Stimulating Factor
}

National Cancer Institute

\section{Source}

National Cancer Institute. Recombinant Colony Stimulating Factor. NCI Thesaurus. Code C387.

Glycoprotein growth factors produced by monocytes, macrophages, or activated lymphocytes that stimulate the proliferation of bone marrow cells and differentiation of stem cells into colonies of granulocytes, monocytes, or macrophages. These substances act in either paracrine or autocrine fashion on marrow cells, appear to act synergistically in complex and poorly understood ways. Each appears to exert actions on several lines of progenitor cells and to influence end cell function. Treatment with colony-stimulating factors (CSF) can help the blood-forming tissue recover from the effects of chemotherapy and radiation therapy. These factors include interleukin-3 (IL-3), granulocyte colony-stimulating factor (G-CSF), macrophage colony-stimulating factor (M-CSF), and granulocyte-macrophage colony-stimulating factor (GM-CSF). 